\title{
Is the processing of words during eye fixations in reading strictly serial?
}

\author{
ALBRECHT W. INHOFF, MATTHEW STARR, and KELLEY L. SHINDLER \\ State University of New York, Binghamton, New York
}

\begin{abstract}
Extant models of oculomotor control during reading maintain that allocation of attention confines word recognition to one (target) word at a time, and that an eye movement to a new (posttarget) word is computed before attention is shifted to it. To test these assumptions, properties of the posttarget's preview were manipulated during the fixation of the preceding target word. The main results revealed longer target viewing durations when the posttarget preview was visually distinctive or when it was orthographically illegal. The meaning of posttarget text did not affect initial target word reading, although it affected the time spent rereading the target. To account for these findings, extant attention-shift models must assume that readers obtain at least visuospatial and orthographic information from a parafovelly visible word before it is attended. This view has shortcomings, however, and several considerations favor less restrictive model assumptions according to which attention can be allocated to more than one word at a time.
\end{abstract}

Reading requires the development of task-specific skills because the written language signal differs fundamentally from the spoken language signal. Auditory speech is dynamic, unfolding in time, and the speech comprehension system receives an ordered sequence of linguistic symbols for processing. The written language signal, by contrast, is static. Several visual symbols are present at a time, and the reader must actively follow word order by moving the eyes along lines of print.

After each movement (saccade), the eyes are relatively stationary (fixated) and linguistic information is obtained. Stlidies examining the range of effective vision during a fixation (the perceptual span) have shown that it includes at least the fixated word and the next (parafoveal) word in the text (for reviews, see Rayner, 1995, 1998; Rayner $\&$ Pollatsek, 1989). Often the parafoveal word is subsequently fixated. When this occurs, readers use information obtained prior to that word's fixation to facilitate processing during its subsequent fixation (this is referred to as parafoveal preview benefit by Rayner and Pollatsek, 1989).

The nature of the parafoveal preview benefit has been examined in studies that manipulated the type of information that could be gleaned from a parafoveally visible word preview. Results of these studies showed that readers spent less time on a word when its prior parafoveal preview revealed useful beginning letter information than

This work was supported by a grant from the National Science Foundation (SBR98101690) and by the center of cognitive and psycholinguistic studies at the State University of New York, Binghamton. We thank Keith Rayner, Francoise Vitu, and an anonymous reviewer for their helpful comments on an earlier version of the manuscript. Correspondence should be addressed to A. W. Inhoff, Department of Psychology, State University of New York, Binghamton, NY 13902-6000 (e-mail: inhoff@binghamton.edu). when it consisted of a sequence of dissimilar letters, indicating that useful graphemic information is obtained (e.g., Briihl \& Inhoff, 1995; Rayner, 1975; Rayner, Well, Pollatsek, \& Bertera, 1982). Other studies revealed shorter viewing durations when a word's parafoveal preview consisted of a word that was homophonic to it than when it consisted of a word that was graphemically similar to the homophone (Pollatsek, Lesch, Morris, \& Rayner, 1992), presumably because readers gleaned orthographic and phonological information from the parafovea. Furthermore, parafoveal preview of a high-frequency word is more useful than preview of a low-frequency word (Inhoff \& Rayner, 1986; Kennison \& Clifton, 1995; Schroyens, Vitu, Brysbaert, \& d'Ydewalle, 1999), presumably because a parafoveal preview can be used to activate lexical representations. The usefulness of a parafoveal preview depends, however, on the ease with which the directly fixated word is processed, preview benefits being smaller when the fixated word is difficult to process than when it is easy to process (Henderson \& Ferreira, 1990; Kennison \& Clifton, 1995; Schroyens et al., 1999).

A class of models of eye movement control during reading, often referred to as attention-shift models, has been proposed that accounts for readers' acquisition of useful information during a fixation and the accrual of parafoveal preview benefits (Henderson \& Ferreira, 1990; Inhoff, Pollatsek, Posner, \& Rayner, 1989; Morrison, 1984; Rayner \& Pollatsek, 1989; Reichle, Pollatsek, Fisher, \& Rayner, 1998). These models assume that acquisition of useful information during reading is controlled by two distinct dynamic systems: one that controls covert attention and one that controls overt saccades. Covert attention confines the word recognition process to a single word at a time and shifts attention to the next word in the text after an attended word has been recognized. The allocation and 
shifting of attention thus provides the text comprehension system with a strictly ordered speech-type sequence of successive words. According to these models, parafoveal preview benefits accrue when attention is shifted to the next (parafoveal) word in the text before a corresponding saccade is executed.

Covert and overt movement dynamics are assumed to be linked to the success of the word recognition processes. In the most recent attention-shift model, the E-Z reader model (Reichle et al., 1998), allocation of attention first leads to the checking of a word's familiarity, after which its identity is determined. Completion of the familiarity check initiates the specification of a saccade to the next word in the text; successful word recognition, occurring at a later point in time, initiates a corresponding shift of attention. Specification of a saccade thus occurs before the attended word has been recognized and before attention is shifted to the parafoveal word. Nevertheless, parafoveal preview benefits can accrue because specification of the saccade takes time. ${ }^{1}$ Hence, preview benefits will accrue when the interval between the attended word's familiarity check and its recognition is shorter than the time spent specifying the saccade. When this occurs, attention will be shifted to the parafoveal word before the eyes land on it.

Furthermore, the model predicts that the usefulness of a parafoveal preview is a function of the ease of the word recognition process. The interval between a word's familiarity check and its successful recognition should be relatively short when the recognition of an attended word is easy. The shifting of attention to the next word in the text will then precede the execution of a corresponding saccade and substantial preview benefits can accumulate. Increases in the difficulty with which the attended word is recognized will increase the interval between the familiarity check and recognition. This will delay the shifting of attention to the next word in the text and decrease the preview benefit.

In the present study, two core assumptions of the E-Z reader model were examined: (1) that attention is confined to one word at a time and (2) that a saccade to the next word in the text is computed before an attended word is recognized. If there were strict seriality in the recognition of successive words of text, then the viewing time of a fixated word (referred to as target word) should not be a function of linguistic properties of the next (posttarget) word. The assumption that saccade programming ensues before the parafoveal word is attended further predicts that linguistic properties of the posttarget word are of no consequence for the specification of a saccade toward it. Together, the two assumptions imply that linguistic properties of a posttarget word cannot affect the viewing of the target; instead, acquisition of useful information from the posttarget word will be expressed solely during posttarget reading, as demonstrated in prior studies of parafoveal preview benefits.

Several prior studies are consistent with the predictions of attention-shift models (Henderson \& Ferreira, 1993;
Rayner, Fischer, \& Pollatsek, 1998). Participants in Henderson and Ferreira's (1993) study read sentences in which a fixated target word was followed by either a short or long posttarget word with either a high- or low-frequency of occurrence. Virtually all targets received a single fixation, the duration of which was independent of the length and word frequency of the posttarget word. Neither visuospatial nor lexical properties of the posttarget word thus affected target viewing. Similarly, Rayner et al. (1998) showed that the word frequency of a posttarget word did not have a discernible effect on target viewing.

Other results, however, are more difficult to reconcile with attention-shift models. Using word comparison tasks, in which the participant determined whether successively fixated words were either physically identical or synonymous, Kennedy (1998) obtained longer target viewing (gaze) durations when word frequency of the posttarget word was high rather than when it was low and longer target viewing durations when the posttarget word was long than when it was short. Instances in which the target received a single fixation further revealed shorter fixations when the beginning trigram of the posttarget word was common than when it was uncommon. Underwood, Binns, and Walker (in press) obtained similar trigram effects in a reading task. Even more striking are effects of parafoveal word meaning on target viewing (Murray, 1998). Using a search-type task, in which a one-word difference in meaning had to be detected between two short sentences, Murray obtained shorter viewing durations on noun targets when the following verb constituted a plausible sentence continuation than when it constituted an implausible continuation. These findings thus indicate that programming of an interword saccade to the parafoveally visible word was not solely a function of the success with which the target was recognized; instead, the decision when to move the eyes to a posttarget word was made after readers obtained visuospatial, orthographic, and lexical information from it.

However, the majority of findings described above were not obtained in reading tasks, and word recognition processes could be a function of task demands. In Kennedy's (1998) word comparison tasks, target refixations occurred on approximately $20 \%$ of the trials, but refixations were virtually absent in Henderson and Ferreira's (1993) reading task. Asking readers to compare individual words could have altered the processing of fixated and parafoveally visible words. Rereading text, required in Murray's (1998) task, is relatively infrequent during normal reading.

In the present study, we determined whether visuospatial, orthographic, and lexical properties of a parafoveally visible posttarget preview affected target viewing during normal reading. This was accomplished by using a boundary paradigm (Rayner, 1975) in which the peripheral and parafoveal preview of a posttarget word was systematically varied while prior text, which included a target word, was fixated. Four preview conditions were created-an uppercase condition in which the posttarget 
Table 1

The Viewing of Target and Posttarget Words in the Four Posttarget Preview Conditions

\section{Baseline Preview Condition:}

He approached the yellow traffic light with some caution.

He approached the yellow traffic light with some caution. *

Uppercase Preview Condition:

He approached the yellow traffic LIGHT with some caution.

He approached the yellow traffic light with some caution.

Dissimilar-Letter Preview Condition:

He approached the yellow traffic qvtqp with some caution.

He approached the yellow traffic light with some caution.

Inconsistent-Context Preview Condition:

He approached the yellow traffic smoke with some caution.

He approached the yellow traffic light with some caution.

Note - Two successive fixations on the target and posttarget words, respectively.

word was shown in visually distinctive uppercase letters before its fixation; a dissimilar-letter condition in which each character of the posttarget word was replaced with a visually dissimilar character, creating an orthographically illegal sequence of letters; a context-inconsistent condition in which the posttarget word was replaced with a semantically unrelated and contextually inappropriate word; and a baseline condition in which the posttarget word was shown in lowercase throughout sentence reading. Eye-movement-contingent display changes were used to replace uppercase, visually dissimilar, and unrelated previews with the lowercase posttarget word when the eyes moved onto the posttarget location. Target and posttarget viewing durations were then examined to determine whether the information provided by a posttarget preview affects prior target viewing durations or whether it affects only subsequent posttarget reading, yielding familiar preview benefits.

The uppercase preview of the posttarget word could influence the time spent viewing the preceding target word (relative to the baseline condition). This could occur either because visuospatial properties of the posttarget preview are coded prior to the allocation of attention to it, which would be in accord with attention-shift models, or because attention is shifted to the visually distinctive preview prior to the computation of a saccade to it, which would not be in accord with attention-shift models. A parafoveally visible quasirandom string of letters is not visually distinctive, and effects of this type of preview on prior target viewing would imply that readers can obtain linguistic (orthographic) information prior to saccade programming. Finally, effects of a contextually unrelated posttarget word on target viewing duration would imply that readers can determine the meaning of a parafoveally visible word prior to its fixation, which would provide unequivocal evidence against attention-shift models.

\section{METHOD}

\section{Participants}

Twenty undergraduate students at the State University of New York, Binghamton were either paid to participate in the experiment or received experimental course credit. All students had uncorrected vision and were native speakers of English.

\section{Materials}

Fifty-two target words were selected, each of which was followed by a related posttarget word-for instance, traffic (target) light (posttarget), circus clown, or garage door. Mean word frequency of target and posttarget (baseline) words equaled 65 and 112 per million (Kučera \& Francis, 1967), respectively, with corresponding standard deviations of 87 and 264 . The length of target words ranged from 3 to 9 letters, with a mean of 5.5 letters. The corresponding length values of posttarget words were 3 to 8 letters, with a mean of 4.9 letters. All target and posttarget words and their pairings were familiar to readers, as judged by four independent raters. Each critical two-word sequence was embedded in a sentence context that contained between 50 and 78 letters so that it could be shown on a single line of text. The critical word sequence occupied neither a sentence-initial nor a sentence-final location. A full listing of the materials is shown in the Appendix.

In the experiment, four versions of the critical word pair were created: one in which the target word (e.g., traffic) was followed by the posttarget word shown in lowercase (light), subsequently referred to as the baseline condition; one in which the target was followed by the posttarget word shown in uppercase $(L I G H T)$, referred to as the uppercase condition; one in which it was followed by a string of lowercase letters that were visually dissimilar from the lowercase posttarget word (gvtqp), referred to as the dissimilarletter condition; and one in which it was followed by a contextually inappropriate word also shown in lowercase (smoke), referred to as the context-inconsistent condition. All posttarget previews were matched for length and all text was shown in 12-point Courier text so that previews with the same number of letters also occupied the same screen area. Eye-movement-contingent display changes were used to present the contextually appropriate posttarget word in all display conditions as soon as the eyes moved to the posttarget location. A sample sentence depicting target and posttarget viewing in the four posttarget viewing conditions is shown in Table 1.

\section{Apparatus}

A NEC 5FGe monitor with .28-mm dot pitch was used to display text. All stimuli were shown in light green on a black background. Text was shown in VGA display mode with a $480 \times 640$ screen resolution. Word Perfect 6.0 for DOS was used to generate and display crisp letters. The distance between the reader's eyes and the monitor was set at $65 \mathrm{~cm}$. At this viewing distance, each letter of text subtended approximately $.33^{\circ}$ of visual angle.

Eye movements were recorded via a fifth-generation dual-Purkinje SRI eye-tracking system (Crane \& Steele, 1985). Viewing was binocular but eye movements were recorded from the right eye only. The system has a relative visual resolution of $\left\langle 10^{\prime}\right.$ of arc and its output was linear over the vertical and horizontal ranges of the visual display. Analog input from the eye tracker was digitized via a Data Translation 2801-A A-to-D converter housed in a personal computer. The computer controlled the visual display and stored horizontal and vertical fixation coordinates in 2-msec intervals. These data were used to determine the size of a lateral saccade to the nearest $1 / 10$ of a letter space and the duration of a fixation to the nearest $2 \mathrm{msec}$.

\section{Procedure}

All participants were tested individually. When a participant arrived in the laboratory, a bite bar was prepared that served to reduce head movements during the experiment. A two-dimensional cali- 
bration of the eye-tracking system began the experiment. During calibration, the reader was asked to fixate five monitor positions (left top, right top, left bottom, right bottom, screen center), displayed sequentially as a series of 12 (vertical) $\times 9$ (horizontal) pixel grids ( .5 and $.37^{\circ}$ of visual angle, respectively). At each fixation location, a sequence of random numbers ranging from 1 to 9 with a maximal extension of $10 \times 7$ pixels $\left(.4 \times .28^{\circ}\right.$ of visual angle $)$ was shown inside the square with each digit being visible between 100 and $400 \mathrm{msec}$. Occasionally, a smaller $(5 \times 4$ pixel $)$ grid $\left(.2^{\circ} \times .17^{\circ}\right.$ of visual angle) was shown for $400 \mathrm{msec}$ inside the outline, and the participant was asked to respond to its onset by pressing the right side of the mouse button. The reader's fixation location was sampled for $150 \mathrm{msec}$ after each mouse key activation when a grid had been visible. This detection routine was repeated for each of the five monitor positions. The $\mathrm{X} / \mathrm{Y}$ A-to-D converter values for the five sampled screen fixations were then mapped onto the corresponding CRT locations. After calibration, five fully illuminated $12 \times 8$ pixel squares $\left(.5^{\circ} \times .33^{\circ}\right.$ of visual angle $)$ were shown, one near each of the four monitor corners and one in the center of the screen. The reader's fixation location was indicated on the screen via a $12 \times 8$ pixel cursor that moved in synchrony with the eyes. The reader was asked to fixate each of the five illuminated locations and was reminded that the task was not to move the cursor onto the illuminated positions but to merely look at each position. The calibration was considered successful when no more than 12 (vertical) and 8 (horizontal) blank pixels intervened between each of the five calibration check positions and the location of the eye-movementcontingent fixation cursor.

After successful calibration, the reader was asked to fixate a $5 \times$ 4 pixel marker at the left side of the screen, then to depress a mouse button to display a line of text. Buttonpressing replaced the fixation marker with a sentence and started the recording of eye positions. After reading was completed, the reader depressed the same mouse key, which erased the line of visible text and terminated the recording of eye movements for the trial. After the reading of approximately every 10 th to 15 th sentence, the reader was asked to release the bite bar and to repeat the previously read sentence. A similar comprehension check procedure has been used in other studies (e.g., Pollatsek et al., 1992). Virtually all sentences were either reported or paraphrased correctly.

Eye-movement-contingent display changes, used to replace the parafoveal preview in the uppercase, dissimilar letter and the contextinconsistent conditions with the posttarget word, were initiated as soon as the eyes were more than $1 / 10$ of a letter to the right of the last letter of the target word. Specification of the display change occurred within the 2-msec sampling cycle, during which the display change criterion was met, but implementation of the display change was not immediate. A custom-developed VGA driver routine was used to refresh 111 of the 480 vertical pixel lines at a rate of $200 \mathrm{~Hz}$, which resulted in a mean display change implementation lag of approximately $5 \mathrm{msec}$. Since the eye generally spent some milliseconds moving after the boundary was crossed, most display changes had already been implemented after the saccade had been completed (the identical display change procedure and hardware setup were used by Inhoff \& Liu, 1998). A systematic investigation of eye-movement-contingent display change effects (Inhoff, Starr, Liu, \& Wang, 1998) also revealed that these changes are unlikely to create artifactual eye movement effects during reading.

\section{Design, Data Selection, \\ Measurements, and Statistical Analyses}

Four lists of sentences were constructed. The lists differed in that a target word was followed by a different type of posttarget word in each of the four lists, with the constraint that each list of sentences contained 13 critical target-posttarget pairings in each of the four experimental conditions. Since most of the experimental sentences led to the implementation of an eye-movement contingent display change, we added 40 filler sentences to each list, none of which contained a display change. Thus each list contained a total of 92 sentences, preceded by a series of practice sentences. The ordering of target-posttarget viewing conditions was randomized for each list, and list assignment was counterbalanced over 4 successive participants.

Fixations of more than 50 and less than $1,500 \mathrm{msec}$ and all saccades exceeding one letter space were included in the analyses. The durations of successive fixations were cumulated into a singlefixation duration value when successive fixations were less than one letter apart. Target-viewing durations as a function of posttarget preview were of primary interest. Four viewing duration measures were obtained, including three first-pass duration measures: first-fixation durations, gaze durations, and single-fixation durations; and a measure that included the time spent rereading the target: total viewing durations. First fixations consisted of the duration of the first fixation on the target, irrespective of whether it was refixated or not. Single-fixation durations measured target viewing in those instances in which the target received exactly one fixation. Gaze durations measured cumulated target viewing duration, including the time spent refixating the target, but they did not include the time spent moving the eyes from one word location to another. ${ }^{2}$ Total viewing durations measured the time spent viewing the target during its first-pass viewing and during subsequent rereadings.

Additional analyses were applied to the size of the saccade to the target, the size of the saccade from the target word to the posttarget preview, to target and posttarget fixation locations, and to posttarget viewing durations. Omnibus analysis of variance (ANOVA) with the factor posttarget preview were applied to all data, followed by paired comparisons in which each of the three preview manipulations was contrasted with the baseline. Error variability was computed over participants and items in all analyses of target-viewing durations; it was computed over participants in all other supplementary analyses.

\section{RESULTS}

\section{Target Reading}

First-fixation durations, single-fixation durations, gaze durations, and total viewing durations on the target word as a function of the parafoveally visible posttarget preview are shown in Table 2. All measures of target viewing revealed effects of posttarget preview, with the omnibus effect being significant in first-fixation durations $[F 1(3,57)=4.00, F 2(3,153)=2.97$, both $p s<.05]$, gaze durations $[F 1(3,57)=4.02, F 2(3,153)=5.46$, both $p \mathrm{~s}<.025]$, total viewing durations ${ }^{3}[F 1(3,57)=8.17$, $F 2(3,153)=10.74$, both $p s<.01]$, and marginally significant in single-fixation durations $[F 1(3,57)=2.19$, $p<.1, F 2(3,153)=3.24, p<.05]$.

Paired comparisons, in which the baseline condition was contrasted with the uppercase preview condition, showed that the visuospatial distinctiveness of the posttarget preview affected target viewing. It increased target first-fixation durations by $15 \mathrm{msec}[t 1(19)=1.46, p<$ $.16, t 2(51)=197, p<.06]$, single-fixation durations by $11 \mathrm{msec}[t 1 \approx 1, t 2(51)=2.38, p<.05]$, gazes by $25 \mathrm{msec}$ $[t 1(19)=2.15, t 2(51)=2.75$, both $p \mathrm{~s}<.05]$, and total viewing durations by $40 \mathrm{msec}[t 1(19)=2.83, t 2(51)=$ 3.50 , both $p \mathrm{~s}<.05]$.

All four measures of target viewing also showed large and robust increases when the posttarget preview consisted 
Table 2

Mean Target Viewing (in Milliseconds) and Standard Errors of the Mean as a Function of the Four Different Types of Posttarget Previews

\begin{tabular}{|c|c|c|c|c|c|c|c|c|}
\hline \multirow{2}{*}{$\begin{array}{c}\text { Fixated } \\
\text { Target Word } \\
\text { (e.g., traffic) }\end{array}$} & \multicolumn{2}{|c|}{$\begin{array}{c}\text { Baseline } \\
\text { Preview } \\
(l i g h t)\end{array}$} & \multicolumn{2}{|c|}{$\begin{array}{c}\text { Uppercase } \\
\text { Preview } \\
(L I G H T) \\
\end{array}$} & \multicolumn{2}{|c|}{$\begin{array}{l}\text { Dissimilar- } \\
\text { Letter } \\
\text { Preview } \\
(q v q p) \\
\end{array}$} & \multicolumn{2}{|c|}{$\begin{array}{c}\text { Context- } \\
\text { Inconsistent } \\
\text { Preview } \\
\text { (smoke) }\end{array}$} \\
\hline & $M$ & $S E M$ & $M$ & $S E M$ & $M$ & $S E M$ & $M$ & $S E M$ \\
\hline $\begin{array}{l}\text { First-fixation } \\
\text { duration }\end{array}$ & 256 & 11 & 272 & 11 & 289 & 10 & 261 & 9 \\
\hline $\begin{array}{l}\text { Single-fixation } \\
\text { duration }\end{array}$ & 273 & 8 & 284 & 13 & 300 & 11 & 283 & 12 \\
\hline Gaze duration & 292 & 10 & 316 & 15 & 326 & 12 & 295 & 12 \\
\hline $\begin{array}{l}\text { Total viewing } \\
\text { duration }\end{array}$ & 308 & 10 & 347 & 21 & 387 & 21 & 348 & 15 \\
\hline
\end{tabular}

of a sequence of quasirandom letters in the dissimilarletter condition. The effect sizes were quite large, amounting to $33 \mathrm{msec}$ in the first-fixation durations $[t 1(19)=$ $3.02, t 2(53)=2.68]$, to $27 \mathrm{msec}$ in the single-fixation durations $[t 1(19)=3.37, t 2(51)=3.01]$, to $34 \mathrm{msec}$ in the gaze durations $[t 1(19)=3.29, t 2(51)=3.57]$, and to almost $80 \mathrm{msec}$ in the total viewing durations $[t 1(19)=4.40$, $t 2(51)=5.57$, all $p \mathrm{~s}<.01]$.

The meaning of the posttarget preview exerted virtually no effect on first-pass target reading, with the difference between the baseline condition and the contextinconsistent condition amounting to less than $10 \mathrm{msec}$ in the first-fixation durations, single-fixation durations, and gaze durations, all $t$ values $<1$. Yet the meaning of the preview affected the time spent rereading the target, the total viewing duration on the target being longer when the posttarget preview was context inconsistent $[t 1(19)=$ $3.21, t 2(51)=2.80$, both $p$ s $<.01]$.

Together, these results indicate that visuospatial and orthographic properties of a posttarget preview affect target reading. Posttarget meaning had no effect on first-pass target reading, but it influenced the time spent rereading the target.

\section{Supplementary Analyses of Target Viewing Durations}

As noted earlier, Kennedy (1998) obtained effects of posttarget word frequency and of posttarget word length on target viewing in word comparison tasks, though corresponding effects were absent in a reading task (Henderson \& Ferreira, 1993; Rayner et al., 1998). Two supplementary analyses of target-viewing duration were conducted to determine whether posttarget word frequency and length affected target viewing in the present study. We also conducted a third analysis to examine whether effects of the posttarget preview on target viewing were a function of the distance of the posttarget preview to the target fixation.

The examination of the effect of posttarget word frequency on target viewing took Kennedy's (1998) suggestion into account, according to which the word frequency of a posttarget word may affect target viewing only when the target is refixated before another word is fixated. Target refixation rates in the present study amounted to .12 , $.14, .11$, and .13 in the baseline, uppercase, dissimilarletter, and context inconsistent preview conditions, respectively. Though these target refixation rates were still lower than in Kennedy's word comparison tasks, we used the present data to determine whether the word frequency of the parafoveally visible posttarget word determined target-viewing durations when the target received a single fixation and when it included trials in which the target either received a single fixation or when it may have been refixated (as may occur in first-fixation durations and gaze durations). A median split was used to create two posttarget word frequency conditions, a low/medium-frequency condition with posttarget word frequencies of less than 50 per million (Kučera \& Francis, 1967) and a high-frequency condition with all other posttarget words. Only the baseline preview condition was of interest, since reading in this condition corresponded to the reading condition in Henderson and Ferreira's (1993) study.

The results revealed nearly identical target-viewing durations irrespective of the posttarget word's frequency. Mean first fixations, gaze durations, and single fixations on target words amounted to 248,286 , and $273 \mathrm{msec}$, respectively, for low/medium-frequency posttarget previews, and to 256,293 , and $273 \mathrm{msec}$ for high-frequency posttarget previews (all $t \mathrm{~s}<1$ ).

Effects of the length of the posttarget preview on target viewing were also relatively small, with target firstfixation durations, single-fixation durations, and gaze durations being 7,9 , and $13 \mathrm{msec}$ longer when the posttarget baseline word was long (containing more than 5 characters). None of these differences was statistically reliable (all $t \mathrm{~s}<1$ ). The results of these two supplementary analyses are thus in general agreement with Henderson and Ferreira's (1993) earlier reports, according to which neither the word frequency nor the length of a parafoveally visible word affects the time spent viewing a fixated word.

In the third supplementary analysis, we examined whether the effects of posttarget previews on target view- 
Table 3

Mean Posttarget Viewing (in Milliseconds) and Standard Errors of the Mean as a Function of the Four Different Types of Posttarget Previews

\begin{tabular}{|c|c|c|c|c|c|c|c|c|}
\hline \multirow{2}{*}{$\begin{array}{l}\text { Posttarget } \\
\text { (e.g., light) }\end{array}$} & \multicolumn{2}{|c|}{$\begin{array}{c}\text { Baseline } \\
\text { Preview } \\
(\text { light })\end{array}$} & \multicolumn{2}{|c|}{$\begin{array}{c}\text { Uppercase } \\
\text { Preview } \\
(L I G H T)\end{array}$} & \multicolumn{2}{|c|}{$\begin{array}{c}\text { Dissimilar- } \\
\text { Letter } \\
\text { Preview } \\
(q v t q p)\end{array}$} & \multicolumn{2}{|c|}{$\begin{array}{c}\text { Context- } \\
\text { Inconsistent } \\
\text { Preview } \\
\text { (smoke) }\end{array}$} \\
\hline & $M$ & $S E M$ & $M$ & $S E M$ & $M$ & SEM & $M$ & $S E M$ \\
\hline $\begin{array}{l}\text { First-fixation } \\
\text { duration }\end{array}$ & 261 & 9 & 276 & 13 & 343 & 20 & 309 & 13 \\
\hline $\begin{array}{l}\text { Single-fixation } \\
\text { duration }\end{array}$ & 261 & 8 & 276 & 14 & 351 & 20 & 311 & 12 \\
\hline $\begin{array}{l}\text { Gazed duration } \\
\text { Total viewing duration }\end{array}$ & $\begin{array}{l}276 \\
297 \\
\end{array}$ & $\begin{array}{l}10 \\
11\end{array}$ & $\begin{array}{l}291 \\
341 \\
\end{array}$ & $\begin{array}{l}15 \\
32 \\
\end{array}$ & $\begin{array}{l}367 \\
436 \\
\end{array}$ & $\begin{array}{l}18 \\
26 \\
\end{array}$ & $\begin{array}{l}336 \\
378 \\
\end{array}$ & $\begin{array}{l}12 \\
15\end{array}$ \\
\hline
\end{tabular}

ing were a function of posttarget eccentricity. In Murray's (1998) study, effects of posttarget preview on target viewing were confined to instances in which the target fixation was relatively close to the posttarget word. Similarly, effects of posttarget meaning could be present in this study only when target fixations were relatively close to the preview.

To test this possibility, the location of single fixations on the target word was determined to select target fixations that were near the posttarget preview. To be considered "near" the preview, the location of a fixation had to be within three character spaces, or approximately $1^{\circ}$ of visual angle, of the blank space preceding the posttarget preview. Only those instances were considered in which the target received a single fixations to avoid effects of repeated viewings. The results showed again longer targetviewing durations when posttarget preview consisted of dissimilar letters ( $314 \mathrm{msec})$ than when it consisted of the baseline preview ( $268 \mathrm{msec})$. Moreover, near fixations were also influenced by posttarget meaning and amounted to $299 \mathrm{msec}$ in the context-inconsistent condition. Although the variability in the reduced set of data was relatively large, both differences were marginally reliable when nondirectional tests were applied $[t(19)=1.95, p<$ .07 , and $t(19)=1.78, p<.09$, respectively]. Near target fixation in the uppercase condition amounted to $289 \mathrm{msec}$ and no longer differed reliably from the baseline condition $(t<1)$.

\section{Posttarget Reading}

Table 3 shows posttarget viewing durations as a function of prior posttarget preview. All measures revealed profound preview effects, with the omnibus effect being significant in first-fixation durations $[F(3,57)=12.55]$, single-fixation durations $[F(3,57)=15.92]$, gaze durations $[F(3,57)=14.13]$, and total viewing durations $[F(3,57)=$ 6.54, all $p$ s $<.01]$.

Parafoveal preview of the posttarget word written in visually distinctive uppercase was as effective as a posttarget preview in lowercase. This was expressed in paired comparisons of the three first-pass posttarget-viewing duration measures (first fixations, gaze durations, single fixations), all of which yielded differences of less than $20 \mathrm{msec}$ (all $p \mathrm{~s}>.2$ ). The difference was larger in the total viewing durations, where it amounted to $44 \mathrm{msec}$, but it remained unreliable due to the relatively large variability in the data $[t(19)=1.31, p>.2]$.

All posttarget viewing durations were substantially increased, however, when the posttarget preview consisted of dissimilar letters. The size of the effect exceeded $80 \mathrm{msec}$ in first-fixation durations $[t(19)=5.49]$, in singlefixation durations $[t(19)=5.67]$, and in gaze durations, and it amounted to $139 \mathrm{msec}$ in total viewing durations $[t(19)=4.68$, all $p$ s $<.01]$.

Parafoveal preview of a context-inconsistent word also increased posttarget viewing durations, since contextinconsistent previews differed from the baseline previews in meaning and graphemic form. The effect size amounted to approximately $50 \mathrm{msec}$ in each of the three first-pass measures, which was reliable in the first-fixation durations $[t(19)=4.23]$, the single-fixation durations $[t(19)=$ $4.63]$, and the gaze durations $[t(19)=5.11$, all $p \mathrm{~s}<.01]$. The effect size increased to $81 \mathrm{msec}$ in total viewing durations $[t(19)=4.44, p<.01]$.

\section{Supplementary Examination of Posttarget Viewing Durations}

As noted, the E- $Z$ reader model predicts that posttarget preview benefits should decrease as the difficulty of target recognition increases. We used target-viewing durations as an index of the target's ease of recognition, with short gaze durations indicating that recognition was relatively easy (see Schroyens et al., 1999, for a similar approach). A median split was applied to target gazes of each reader to create one group of short target gazes $(M=224 \mathrm{msec})$ and another group of long gazes $(M=$ $378 \mathrm{msec}$ ). The three first-pass posttarget reading measures were then analyzed as a function of target gaze durations (short vs. long) and posttarget preview.

The results of this analysis are shown in Table 4. There was some noise in the data, but comparisons of the baseline condition with the other preview conditions indi- 
Table 4

Mean First-Pass Posttarget Reading Times (in Milliseconds) and Standard Errors of the Mean as a Function of the Prior Target Gaze Duration (Short vs. Long) and Posttarget Preview

\begin{tabular}{|c|c|c|c|c|c|c|c|c|}
\hline \multirow[b]{2}{*}{ Posttarget (light) } & \multicolumn{2}{|c|}{$\begin{array}{c}\text { Baseline } \\
\text { Preview } \\
(\text { light })\end{array}$} & \multicolumn{2}{|c|}{$\begin{array}{c}\text { Uppercase } \\
(L I G H T)\end{array}$} & \multicolumn{2}{|c|}{$\begin{array}{c}\text { Dissimilar- } \\
\text { Letter } \\
(\text { gvtqp }) \\
\end{array}$} & \multicolumn{2}{|c|}{$\begin{array}{c}\text { Context- } \\
\text { Inconsisten } \\
(\text { smoke })\end{array}$} \\
\hline & $M$ & $S E M$ & $M$ & $S E M$ & $M$ & $S E M$ & $M$ & $S E M$ \\
\hline \multicolumn{9}{|c|}{ First-Fixation Duration } \\
\hline Short & 253 & 10 & 277 & 20 & 330 & 23 & 300 & 15 \\
\hline Long & 250 & 13 & 279 & 17 & 338 & 22 & 332 & 19 \\
\hline \multicolumn{9}{|c|}{ Single-Fixation Duration } \\
\hline Short & 255 & 10 & 275 & 20 & 332 & 22 & 305 & 14 \\
\hline Long & 250 & 13 & 283 & 17 & 346 & 23 & 306 & 13 \\
\hline \multicolumn{9}{|l|}{ Gaze Duration } \\
\hline Short & 277 & 15 & 281 & 20 & 337 & 21 & 330 & 17 \\
\hline Long & 253 & 15 & 295 & 20 & 370 & 21 & 333 & 19 \\
\hline
\end{tabular}

cated that posttarget preview benefits tended to be larger, rather than shorter, when target-viewing durations had been long.

The largest effect of target-viewing duration emerged in the gaze data, where the difference between the baseline and dissimilar-letter conditions amounted to $117 \mathrm{msec}$ when the prior target duration had been long and to $60 \mathrm{msec}$ when it had been short. The corresponding interaction of target duration and posttarget preview was marginally significant $[F(1,19)=4.14, p<.056]$. The effects of target duration were smaller in all other comparisons, none of which approached significance (all $p \mathrm{~s}>.2$ ).

Together these results are consistent with previously reported data regarding parafoveal preview benefits (e.g., Rayner, McConkie, \& Zola, 1980; Schroyens et al., 1999 ) in that less time was spent viewing a (posttarget) word when prior parafoveal preview revealed its letters, as occurred in the baseline and uppercase conditions than when no useful letter information was provided, as occurred in the dissimilar-letter and context-inconsistent conditions. Supplementary results also showed that post- target preview benefits tended to be larger rather than smaller when the prior target-viewing durations were long.

\section{Moving the Eyes From}

\section{the Target Word to the Posttarget Preview}

The location of the initial fixation on a word has an effect on its viewing duration (McConkie, Kerr, Reddix, Zola, \& Jacobs, 1989; Vitu, O'Regan, \& Mittau, 1990). Effects of posttarget preview on target-viewing duration in the present study could thus be compromised if target fixation locations were a function of posttarget preview type. Similarly, viewing location differences could hamper the interpretation of parafoveal preview benefits. To examine these possibilities, we computed two saccade sizes, one that positioned the eyes on the target and one that positioned the eyes on the posttarget word. Furthermore, we analyzed the resulting viewing location differences as a function of posttarget preview. The results are shown in Table 5.

The analysis of saccades to targets revealed a mean size of 8.4 letter spaces, which positioned the eyes near the

Table 5

The Mean Size of Interword Saccades (in Letter Spaces) and the Subsequent Fixation Locations on Target and Posttarget Words as a Function of the Parafoveal Preview of the Posttarget Word and Standard Errors of the Mean

\begin{tabular}{|c|c|c|c|c|c|c|c|c|}
\hline \multirow{2}{*}{$\begin{array}{c}\text { Posttarget Word } \\
\text { (e.g., light) }\end{array}$} & \multicolumn{2}{|c|}{$\begin{array}{c}\text { Baseline } \\
\text { Preview } \\
(\text { light })\end{array}$} & \multicolumn{2}{|c|}{$\begin{array}{c}\text { Uppercase } \\
\text { Preview } \\
(L I G H T)\end{array}$} & \multicolumn{2}{|c|}{$\begin{array}{c}\text { Dissimilar- } \\
\text { Letter } \\
\text { Preview } \\
(q v t q p) \\
\end{array}$} & \multicolumn{2}{|c|}{$\begin{array}{c}\text { Context- } \\
\text { Inconsisten } \\
\text { Preview } \\
(\text { smoke }) \\
\end{array}$} \\
\hline & $M$ & $S E M$ & $M$ & $S E M$ & $M$ & $S E M$ & $M$ & $S E M$ \\
\hline $\begin{array}{l}\text { Saccade to } \\
\text { target }\end{array}$ & 8.2 & .5 & 7.7 & .5 & 8.0 & .5 & 8.7 & .2 \\
\hline $\begin{array}{l}\text { Initial target } \\
\text { viewing location }\end{array}$ & 2.6 & .2 & 2.4 & .2 & 2.5 & .2 & 2.8 & .1 \\
\hline $\begin{array}{l}\text { Saccade to } \\
\text { posttarget word }\end{array}$ & 7.7 & .4 & 6.7 & .5 & 7.1 & .4 & 7.3 & .4 \\
\hline $\begin{array}{l}\text { Initial posttarget } \\
\text { viewing location }\end{array}$ & 2.5 & .2 & 2.1 & .2 & 2.5 & .2 & 2.5 & .2 \\
\hline
\end{tabular}


word center. Relative to the baseline condition, saccades were slightly smaller in the uppercase posttarget preview condition and slightly larger in the inconsistent-context preview condition. Overall, the omnibus ANOVA revealed a main effect $[F(3,57)=4.47, p<.01]$, but paired comparisons of the baseline condition with the other three preview conditions did not yield a reliable difference (all $t \mathrm{~s}<1$ ).

Saccades from the target to the posttarget preview amounted to 7.2 letter spaces and positioned the eyes near the word center. The effects of parafoveal preview on saccade size were robust $[F(3,57)=2.90, p<.05]$. Paired comparisons, with the baseline condition as referent, revealed significantly shorter saccades in the uppercase preview condition $[t(19)=2.63, p<.05]$. None of the remaining contrasts approached significance (all $t \mathrm{~s}<1$ ). Corresponding effects emerged in the analysis of posttarget viewing locations, where the initial landing position was shifted toward the word beginning in the uppercase condition. Though the omnibus ANOVA did not yield a reliable effect $[F(3,57)=1.80, p<.18]$, the paired comparison of base and uppercase conditions yielded a reliable difference $[t(19)=3.63, p<.01]$.

These results indicate that target-viewing durations were generally not compromised by fixation location differences, except that visually distinct uppercase previews resulted in slightly shorter movements.

\section{DISCUSSION}

The main results of the present study were straightforward: The properties of a parafoveally visible posttarget preview affected target and posttarget reading. The time spent viewing a target during its first-pass reading increased when the posttarget preview consisted of a word written in uppercase and when it consisted of a string of quasirandom letters. Not all properties of a posttarget preview affected target reading, however. Firstpass target-viewing durations remained largely unaffected by the contextual fit of the parafoveally visible posttarget word, unless the target's fixation was within $1^{\circ}$ of the onset of the posttarget word. Target-viewing durations were also unaffected by the word frequency and the length of the posttarget word. Previously reported effects of the posttarget preview on subsequent posttarget reading were also present and expressed in shorter posttargetviewing durations when the prior preview of the posttarget word revealed useful letters, as occurred in the baseline and uppercase conditions, than when no useful letter information was provided.

The majority of the findings appear to be in general agreement with the E- $Z$ reader model. The model maintains that covert attention is confined to one word at a time until it is recognized, and that the saccade to the parafoveally visible posttarget preview is computed before attention is shifted to it. Consequently, effects of posttarget meaning on target viewing should be negligible, as should be effects of word frequency. Visuospatial and or- thographic analyses of the posttarget preview during the target's fixation may not require attention. If this were the case, readers could have noted the distinctiveness of uppercase previews and the illegality of dissimilar previews prior to having allocated attention.

The results of two supplementary analyses pose difficulties, however. According to the $\mathrm{E}-\mathrm{Z}$ reader model, preview benefits should have decreased as target-viewing durations increased, since less time can be spent analyzing the preview when the fixated word is difficult to recognize. Yet, preview benefits during posttarget reading tended to be larger when the target gaze durations were relatively long. Furthermore, as in Murray (1998), the meaning of the posttarget word influenced target viewing in the present study when the location of the target fixation was near the preview in the context-inconsistent preview condition. Again, this should not occur according to the E-Z reader model, in which acquisition of word meaning is assumed to require attention and the saccade to a parafoveal preview is programmed before the preview is attended. In defense of the $E-Z$ reader model, it could be argued that the two supplementary analyses are based on a small set of data that suffered from large variability. Furthermore, some of the fixations that landed near the posttarget word could have been "undershoots" that had been directed at the posttarget word.

Other considerations reveal additional difficulties for the $E-Z$ reader model. Specifically, results of related work show that the difficulty with which an attended word is recognized influences the usefulness of parafoveally available orthographic information. In Henderson and Ferreira's (1990) Experiment 2, preview benefits, assessed by comparing a baseline condition with a dissimilar-letter preview condition, amounted to $26 \mathrm{msec}$ when the previously fixated target was easy to process and to $-4 \mathrm{msec}$ when it was difficult to process. If use of parafovelly available orthographic information had occurred prior to the allocation of attention to it, then the difficulty with which the fixated target was recognized should not have had an effect on the usefulness of parafoveally visible orthographic information. Hence, the sizable (30-msec) difference in the preview effects of Henderson and Ferreira's (1990) second experiment suggests that acquisition of useful orthographic information from the parafoveal preview does demand attention. Consequently, longer target-viewing durations in the dissimilarletter preview condition of the present study cannot be justified on the grounds that orthographic analysis of the posttarget preview occurred prior to the allocation of attention.

The previously stated ad hoc assumption that readers glean useful orthographic information from a parafoveal preview prior to the allocation of attention to it also implies that the linguistic analysis of the preview can be discontinuous. Specifically, discontinuities in the linguistic analysis of a parafoveal word preview could arise whenever its orthographic analyses are completed before attention is shifted from the fixated to the previewed 
word. When this occurs, all attention-demanding analyses, including the accessing of the previewed word's lexical representation, would have to enter a wait state until attention arrived. The "waiting-for-attention" state would have to be entered and maintained, irrespective of the success with which the orthographic analysis of the posttarget word progressed prior to the arrival of attention and irrespective of the temporal availability of the parafoveal preview.

There is little evidence for the existence of such a wait state, however, and results of our supplementary analyses indicate that lexical information can be extracted from the preview under some conditions. Other results from our laboratory (Inhoff, Radach, Starr, \& Greenberg, in press) also indicate that the analysis of a parafoveally previewed word need not be arrested at an orthographic level before a saccade to it is programmed. In the experiment, readers spent less time viewing a target during sentence reading when it was highly associated with the adjacent posttarget word (e.g., mother's father or doctor's nurse) than when the two words were not associated (mother's garden, doctor's purse). Notably, this effect occurred irrespective of whether the target fixation was relatively near to or relatively far from the posttarget word.

Attention-shift models could be modified to accommodate the present results. Specifically, they could be revised so that attention is shifted to a parafoveally visible posttarget preview before the saccade to it is computed. Visuospatial, orthographic, and lexical properties of a posttarget preview could then affect the decision when to move the eyes to it. The achieved gain in explanatory power is accompanied, however, by a substantial loss. Specifically, effects of the ease of target processing on the magnitude of parafoveal preview benefits (Henderson \& Ferreira, 1990; Kennison \& Clifton, 1995; Schroyens et al., 1999) can now no longer be explained. If the saccade to the posttarget preview was computed after attention was shifted to the preview, then the magnitude of the preview benefit should no longer be a function of the ease with which a fixated word was recognized, since the fixated word is no longer the attended unit when the saccade is computed.

Rather than assuming that a word-size spotlight of attention confines word recognition to individual words of text and that the computation of a saccade to the next word in the text precedes a corresponding shift of a spotlight of attention (Henderson \& Ferreira, 1990; Morrison, 1984; Reichle et al., 1998), we propose that attention is allocated to all words within the perceptual span and that saccades are programmed toward an attended rather than an unattended word. ${ }^{4}$ Allocation of attention does not need to be evenly distributed. The fixated word offers the highest visual resolution, and more attention may be allocated to it than to other words within the perceptual span to achieve relatively quick word recognition. In addition, visuospatial and linguistic properties of text could determine the allocation of attention, so that more resources are allocated to a word when its perceptual and linguistic analyses are difficult. The initial assessment of the familiarity of all words within the perceptual span, or the use of another index of the ease of perceptual and linguistic analyses of all attended words, could be used to initiate the programming of a saccade. Preview benefits will thus be relatively small when a fixated target word is difficult to process and is resource demanding (Henderson \& Ferreira, 1990; Kennison \& Clifton, 1995; Schroyens et al., 1999), although relatively long target-viewing durations will also increase the opportunity for the acquisition of useful information from the parafovea (Inhoff, Topolski, \& Wang, 1992; Schroyens et al., 1999).

In the present study, the bulk of attention may have been allocated to the fixated target. However, since some attention could also be allocated to the posttarget preview, visuospatial, orthographic, and lexical properties of the posttarget preview could have influenced target viewing. If attention was allocated to the posttarget preview throughout target viewing, then preview benefits during posttarget reading could also increase with target-viewing durations.

This view of attention allocation during a fixation is similar to LaBerge and Brown's (1989; LaBerge, Brown, Carter, \& Bash, 1991) conception, according to which resources can be allocated to more than one unit. LaBerge and Brown have suggested that viewers estimate the importance of different segments of a visual array with the highest value being assigned to the most important segment and progressively lower values being assigned to spatially adjacent neighbors. Attention is then allocated accordingly, peaking at the unit with the highest importance value and decreasing over adjacent units.

The gradient of attention must dynamically change when text is read. This could be accomplished by resetting the gradient when a word within the perceptual span has been recognized. This would free resources that could then be allocated to other words within the span. Generally, this would lead to redistribution of attention from the fixated word to the next word in the text. In accord with attention-shift models, dynamic changes in the allocation of attention would thus progress with word order, although our view implies that successively attended areas of text are overlapping rather than nonoverlapping.

Rather than being qualitatively different, the gradientshift conception can be considered a generalized version of the present spotlight conception. On occasion, the gradient could confine linguistic analyses to a single unit - for example, when a fixated word is exceedingly difficult to process. In this case, all resources could be allocated to a fixated unit until it is recognized, and successively attended areas of text would be nonoverlapping.

\section{REFERENCES}

BRIIHL, D., \& INHOFF, A. W. (1995). Integrating information across fixations during reading: The use of orthographic bodies and of exterior letters. Journal of Experimental Psychology: Learning, Cognition. \& Memory, 21, 55-67. 
Crane, H., \& Steele, C. M. (1985). Generation V dual Purkinje-image eyetracker. Applied Optics, 24, 527-537.

Henderson, J. M., \& Ferreira, F. (1990). Effects of foveal processing difficulty on the perceptual span in reading: Implications for attention and eye movement control. Journal of Experimental Psychology: Learning, Memory, \& Cognition, 17, 417-429.

Henderson J. M., \& Ferreira, F. (1993). Eye movement control during reading: Fixation measures reflect foveal but not parafoveal processing. Canadian Journal of Experimental Psychology, 47, 201-221.

INHOFF, A. W., \& LIU, W. (1998). The perceptual span and oculomotor activity during the reading of Chinese sentences. Journal of Experimental Psychology: Human Perception \& Performance, 24, 20-34.

Inhoff, A. W., Pollatsek, A., Posner, M. I., \& Rayner, K. (1989). Covert attention and eye movements during reading. Quarterly Journal of Experimental Psychology, 41A, 63-89.

Inhoff, A. W., Radach, R., \& Heller, D. (2000). Complex compounds in German: Interword spaces facilitate segmentation but hinder assignment of meaning. Journal of Memory \& Language, 42, 23 50.

INHOFF, A. W., Radach, R., StaRR, M., \& GreenberG, S. (in press). Allocation of visuospatial attention and saccade programming in reading. In A. Kennedy, R. Radach, D. Heller, \& J. Pynte (Eds.), Reading as a visual process. Oxford: Elsevier.

INHOFF, A. W., \& RAYNER, K. (1986). Parafoveal word processing during eye fixations in reading: Effects of word frequency. Perception \& Psychophysics, 40, 431-439.

InhoFf, A. W., STARR, M., LiU, W., \& WANG, J. (1998). Eye-movementcontingent display changes are not compromised by flicker and phosphor persistence. Psychonomic Bulletin \& Review, 5, 101-106.

INHOFF, A. W., TOPOLSKI, R., \& WANG, J. (1992). Saccade programming during short fixation durations: An examination of copytyping, letter detection, and reading. Acta Psychologica, 81, 1-21.

KENNEDY, A. (1998). The influence of parafoveal words on foveal inspection time: Evidence for a processing trade-off. In G. Underwood (Ed.), Eye guidance in reading and scene perception (pp. 149-180). Oxford: Elsevier.

Kennison, S. M., \& Clifton, C. (1995). Determinants of parafoveal preview benefit in high and low working memory capacity readers: Implications for eye movement control. Journal of Experimental Psychology: Learning, Memory, \& Cognition, 21, 68-81.

KuČera, H., \& Francis, W. N. (1967). Computational analysis of present-day American English. Providence: Brown University Press.

LABERGE, D., \& Brown, V. (1989). Theory of attentional operations in shape identification. Psychological Review, 96, 101-124.

LaBerge, D., Brown, V., Carter, M., \& Bash, D. (1991). Reducing the effects of adjacent distractors by narrowing attention. Journal of Experimental Psychology: Human Perception \& Performance, 17, 65-76.

McConkie, G. W., KerR, P. W., Reddix, M. D., Zola, D., \& Jacobs, A. M. (1989). Eye movement control during reading: II. Frequency of refixating a word. Perception \& Psychophysics, 46, 245-253.

MoRRISON, R. E. (1984). Manipulation of stimulus onset delay in reading: Evidence for parallel programming of saccades. Journal of Experimental Psychology: Human Perception \& Performance, 10, 667-682.

Murray, W. S. (1998). Parafoveal pragmatics. In G. Underwood (Ed.), Eye guidance in reading and scene perception (pp. 181-200). Oxford: Elsevier.

Pollatsek, A., Lesch, M., Morris, R., \& Rayner, K. (1992). Phonological codes are used in integrating information across saccades in word identification and reading. Journal of Experimental Psychology: Human Perception \& Performance, 18, 148-162.
RAYNER, K. (1975). The perceptual span and peripheral cues in reading. Cognitive Psychology, 7, 65-81.

RAYNER, K. (1995). Eye movements and cognitive processes in reading, visual search, and scene perception. In J. Findlay et al. (Eds.), Eye movement research: Mechanisms, processes and applications (pp. 322). Amsterdam: Elsevier-North Holland.

RAYNER, K. (1998). Eye movements in reading and information processing: Twenty years of research. Psychological Bulletin, 124, 372-422.

Rayner, K., Fischer, M., \& Pollatsek, A. (1998). Unspaced text interferes with both word identification and eye movement control. $\mathrm{Vi}$ sion Research, 38, 1129-1144.

RAYNER, K., MCCONKIE, G. W., \& ZOLA, D. (1980). Integrating information across eye movements. Cognitive Psychology, 12, 206-226.

Rayner, K., \& Pollatsek, A. (1989). The psychology of reading. Englewood Cliffs, NJ: Prentice-Hall.

Rayner, K., Well, A. D., Pollatsek, A., \& Bertera, J. H. (1982). The availability of useful information to the right of fixation in reading. Perception \& Psychophysics, 31, 537-550.

Reichle, E. D., Pollatsek, A., Fisher, D. L., \& Rayner, K. (1998). Towards a model of eye movement control in reading. Psychological Review, 105, 125-157.

Schroyens, W., Vitu, F., Brysbaert, M., \& D'Ydewalle, G. (1999). Eye movement control during reading: Foveal load and parafoveal processing. Quarterly Journal of Experimental Psychology, 52A, $1021-1046$.

UNDERWOOD, G., BINNS, A., \& WALKER, S. (in press). Attention demands on the processing of neighbouring words. In A. Kennedy, R. Radach, D. Heller, \& J. Pynte (Eds.), Reading as a visual process. Oxford: Elsevier.

Vitu, F., O'Regan, J. K., \& MitTaU, M. (1990). Optimal landing position in reading isolated words and continuous text. Perception \& Psychophysics, 47, 583-600.

\section{NOTES}

1. Reichle et al. (1998) discriminated two stages of saccade specification: an initial phase during which the saccade is parameterized and during which the saccade program can be changed, referred to as the $l a-$ bile phase, and a subsequent nonlabile phase during which the saccade program can no longer be altered. Similarly, Morrison (1984) distinguished between saccade initiation and saccade computation, and we use the term saccade computation to refer to the state of saccade programming during which the movement can no longer be altered.

2. We (Inhoff, Radach, \& Heller, 2000) compared gaze durations on very long words (18-24 letters) that either included or excluded the time spent moving the eyes during target refixations. Gazes were longer when the time spent moving the eyes was included, since target words received approximately four fixations on average. However, effect sizes were virtually identical, irrespective of whether the time spent moving the eyes was included.

3. All effect sizes were larger in the total viewing durations than in the other three first-pass viewing duration measures. Overall, rereading occurred on $18 \%$ of the trials, but the bulk of target rereading was performed by five readers. First-pass reading effects did not change when these readers were excluded from the omnibus analyses of first-pass target-viewing durations.

4. A revised version of the spotlight model could also be envisioned in which the size of the spotlight is dynamically changing, so that it encompasses either a single word or several word units. It is not clear. however, from the current $E-Z$ reader model how the size of the spotlight could be adjusted during individual fixations. 


\section{APPENDIX}

Sentences Used in the Experiment

Critical word sequences are shown in bold face. These words were not shown in bold face during the experiment.

My grandmother made us a delicious pumpkin pie for dessert.

My new computer's disk drive is removable.

They liked the taste of Swiss cheese with lots of ham.

Those thin guitar strings you buy break too easily.

Did you see the tennis ball soar over the fence?

I'll bet the leading race car will not win the race.

The newly installed kitchen sink never leaked any water.

Lisa had a painful bee sting on her hand.

Our intoxicated taxi driver ran through three red lights.

I jumped into the freezing bath water this morning.

She told me to mix the cake batter in a clockwise direction.

A defect in our expensive record player ruined our records.

He told us that our metallic curtain rods were simply hideous.

Please make sure the shower curtain is pulled all of the way.

We saw the deadly lightning bolt strike the tree branch.

I saw a horrible traffic accident on the corner of my street.

You can open the garage door with this remote control.

The delicious apple juice was in the refrigerator.

I enjoy walking along train tracks when there are no trains.

Each one of these delicate flower petals has a distinct shape.

My brother's bright computer screen emitted too much radiation.

Eric kicked the empty soda can under the car.

Can you see the reflection in the window pane on the first floor?

I don't like eating the thick bread crust on my sandwiches.

The brightness of the moon light was sufficient to read.

Look what was on the original dollar bill and you'll be surprised.

The dangerous job of lion tamer is dying out.

Drive carefully, the familiar traffic light is switched off.

Where's the white garbage pail that belongs in the bathroom?

Every homeowner loves green grass and hates weeds.

In the church, the faint candle light illuminated one corner.

They had watched a video tape of the whole episode.

He joined the fashionable new health club near his work.

He got a job as a medical doctor at John's Hopkins.

We all gasped as the hockey puck hit the spectator.

We were assured of getting an aisle seat at the play.

Tests show that vegetarian health food can increase fitness.

He used a plastic paper clip to tighten a screw.

They selected a wooden picture frame for their wedding picture.

Bill's old baseball bat was signed by his favorite player.

I heard Mary's barking dog from next door.

The clothes of a professional circus clown are hard to wear.

She read her favorite fairy tale to her little nephew.

Her duties were basically office work and welcoming visitors.

My mother's favorite ski resort is in Vermont.

She liked her potatoes with plenty of sour cream on the top.

My boss told me to buy another file cabinet for the office.

John had to drive his battered snow plow all night.

The moonless black night made it difficult to drive.

There are low-energy light bulbs on the market today.

Can you see the squirrel on the topmost tree branch over there?

I felt a painful head ache start to develop. 